Article

\title{
Surgical Treatment of Displaced Supracondylar Pediatric Humerus Fractures: Comparison of Two Pinning Techniques
}

\author{
Vito Pavone *, Maria Riccioli, Gianluca Testa, Ludovico Lucenti, Claudia de Cristo, \\ Giuseppe Condorelli, Sergio Avondo and Giuseppe Sessa \\ Received: 3 December 2015; Accepted: 6 January 2016; Published: 8 January 2016 \\ Academic Editor: Giuseppe Musumeci \\ Department of Orthopedics, University of Catania, Via Plebiscito, 628, 95124 Catania, Italy; \\ marywe@hotmail.it (M.R.); gianpavel@hotmail.com (G.T.); ludovico.lucenti@gmail.com (L.L.); \\ decristo.claudia@gmail.com (C.C.); dott.condorelli@libero.it (G.C.); sergio.avondo@tin.it (S.A.); \\ giusessa@unict.it (G.S.) \\ * Correspondence: vitopavone@hotmail.com; Tel: +39-095-7435240
}

\begin{abstract}
The aim of this study is to report the results of the treatment of displaced supracondylar humerus fractures comparing two different techniques, crossed and lateral pins. We retrospectively reviewed 35 children hospitalized between May 2005 and December 2012. Patients were treated with two different pin configurations, crossed (Group 1) and lateral (Group 2). After surgery, clinical and radiographic evaluation was performed. Postoperatively, the clinical assessment showed recovery of joint function of the elbow. Radiographically, Group 1 showed a difference in the Baumann angle between the value of the injured limb and the normal angle of $5.3^{\circ} \pm 2.12^{\circ}$; in Group 2 the difference was $4.9^{\circ} \pm 2.82^{\circ}$. Complications: group 1 , two cases of short paresthesia, one case of slight varus, mild asymmetry, and deficit to extension of the humerus and group 2, two cases of local infection and one of a slight hyperextension were reported. Both groups achieved a satisfying outcome with similar results in joint function recovery and complications.
\end{abstract}

Keywords: distal humerus; supracondylar fractures; bone fractures; pinning techniques; fractures

\section{Introduction}

Supracondylar humerus fractures (SCHF) are common injury in children and represent the most frequent fractures involving the elbow [1-3]. These fractures affect mainly the male gender and occur prevalently in consequence of an extension mechanism [4]. The current treatment of displaced supracondylar fractures consists of closed reduction and percutaneous pin fixation using Kirschner wires, while some controversies still exist regarding the placement of the pins [5-7].

Percutaneous pinning has proven to be the least invasive and safest techniques for bone healing. It is characterized by a low incidence of complications $(2 \%-8 \%)$ and mainly consisting of pin migration under the skin, pin infections and loss of fracture reduction [8,9]. Only in cases of open fractures, irreducible fractures by interposition of soft tissues or in cases of possible neurovascular complications, should open surgery interventions be performed as soon as possible [10-12].

Controversy still exists about the optimal placement of the pins. A crossed-pin technique is thought to be mechanically more stable than lateral pin alone even if with the use of the last one, the ulnar nerve could be more easily injured. Slobogean et al. [12] suggest that there is a greater risk of iatrogenic ulnar nerve injury with crossed pinning versus lateral pinning in children with SCHF. 
The aim of this study is to clinically and radiographically compare the effectiveness of SCHF treatment and the complications using the two more common percutaneous K-wire pinning: cross and lateral configurations.

\section{Patients and Methods}

During the period between May 2005 and December 2012, 35 patients were examined at the Orthopedic Clinic of the University of Catania. All subjects gave their informed consent for inclusion before they participated in the study. The study was conducted in accordance with the Declaration of Helsinki, and the protocol was approved by the Ethics Committee of Catania.

The exclusion criteria concerned open fractures of the distal humerus, patients who were adolescents or older at the time of injury, and patients with multiple bone injuries that required multidisciplinary treatment and/or admission to intensive care.

Age at time of surgery, gender, side injured, mechanism of injury, and type of fracture according to Gartland classification were reported. The direction of fracture displacement, time between injury and surgery, time from injury to admission, and the onset of major complications were collected using clinical and radiographic data and parental information on the lesion dynamics. Patients underwent clinical examination and conventional radiography of the anteroposterior and lateral side of the affected limb.

All patients were surgically treated, using a closed reduction and fixation with K-wires. Two different pin configurations, cross (Group 1) and lateral (Group 2).

All treated subjects were evaluated clinically according to Flynn's criteria [13] and the Mayo Elbow Performance Score (0-100 points) [14,15] and radiographically (including the measurement of the Baumann angle) [16]. All patients were assessed at 1, 3, 6, and 12 months, and then every year. The statistical significance of the results was analyzed by the independent sample Student's $t$-test and Fisher's exact test. A $p$ value of $<0.05$ was considered to be statistically significant.

\section{Results}

The average age of the patients was 6 years (range 2.4-8.9), and the cohort comprised 25 males $(72.4 \%)$ and 10 females $(27.6 \%)$ with displaced supracondylar fractures of the humerus (all with Gartland type III fractures) (Figure 1A,B). In 24 patients (69\%) the involved limb was on the left and in $11(31 \%)$ cases on the right. The fractures were linked to a trauma in extension resulting from a fall on the palm of the hand with a hyperextended elbow. This occurred in games in $31(89.6 \%)$ and motor vehicle accidents in $4(10.4 \%)$. Regarding the direction of displacement, there were $28(79 \%)$ fractures of type IIIA and 7 (21\%) of IIIB.
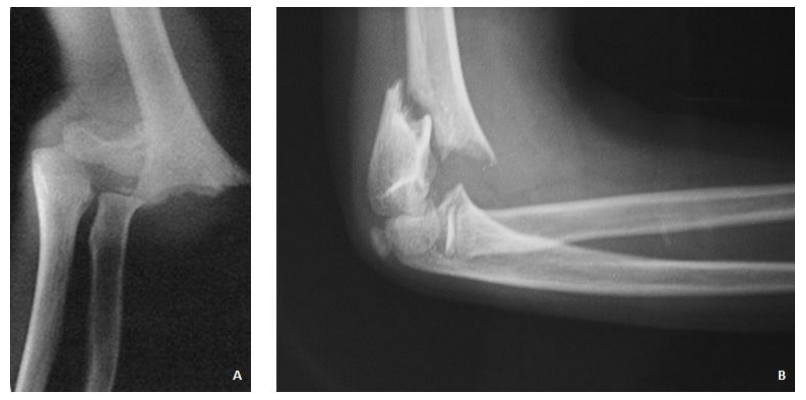

Figure 1. Anteroposterior (A) and lateral (B) radiographs of a patient with a Gartland type III fracture surgically treated eight hours after presentation.

All subjects were treated within eight hours of presentation with a closed reduction and percutaneous pin fixation. After inducing general anesthesia, the patients were positioned in a supine position at the edge of the operating table with the affected limb thoroughly supported by 
the side. The arm was positioned at a " $\mathrm{C}$ " on the brightness amplifier plate. A closed reduction and fixation with 1.6 to $2 \mathrm{~mm} \mathrm{~K}$-wire were used according to the young age of the patients. In the cross pin configuration, the first wire was positioned at the center of the lateral condyle and the second wire was medially inserted taking care to not injure the ulnar nerve. To avoid this complication, a landmark for the insertion of the medial wire was the small area of the medial epicondyle in which the pin must be positioned as far anterior as possible. Using the lateral pin configuration, the first pin was placed centrally and just lateral to the olecranon; the second pin was inserted laterally.

For both configurations (crossed and lateral pins), the wires were positioned distant from each other and careful attention was given to ensure that the pins did not cross the fracture at the same point. After stabilization with wires, the children were immobilized with a simple posterior splint at 90 degrees of flexion. The goal was to optimize perfusion and minimize swelling. In all cases, K-wires protruded outside the wound.

The children, belonging to this study, were randomly submitted to two different wires techniques: 22 patients $(62.1 \%)$ were treated by closed reduction and percutaneous fixation with the crossed wires technique (Group 1) (Figure 2A,B) and 13 (37.9\%) had the lateral-wire configuration (Group 2) (Figure $3 \mathrm{~A}, \mathrm{~B})$. The average age of the 22 children forming Group 1 was $6.26 \pm 2.48$ including 16 males $(72.4 \%)$ and 6 females (27.6\%). Group 2 consisted of 13 children aged $5.69 \pm 2.52$ years on average and comprised 9 males $(72.7 \%)$ and 4 females $(27.3 \%)$. There were no substantial differences between the groups in terms of age, sex, or injured limb.
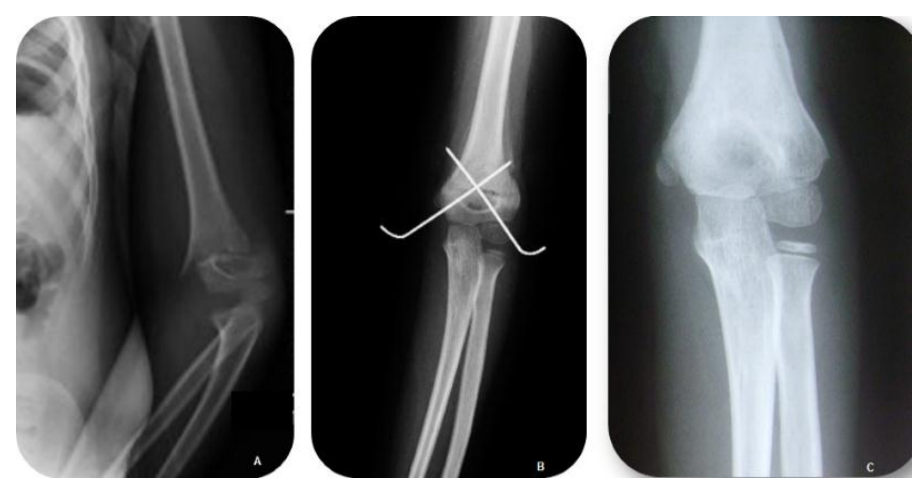

Figure 2. Clinical Case Group 1. (A) Pre-op AP radiograph of crossed pinning; (B) immediate postoperative AP radiograph of crossed pinning; and (C) follow-up after three years.

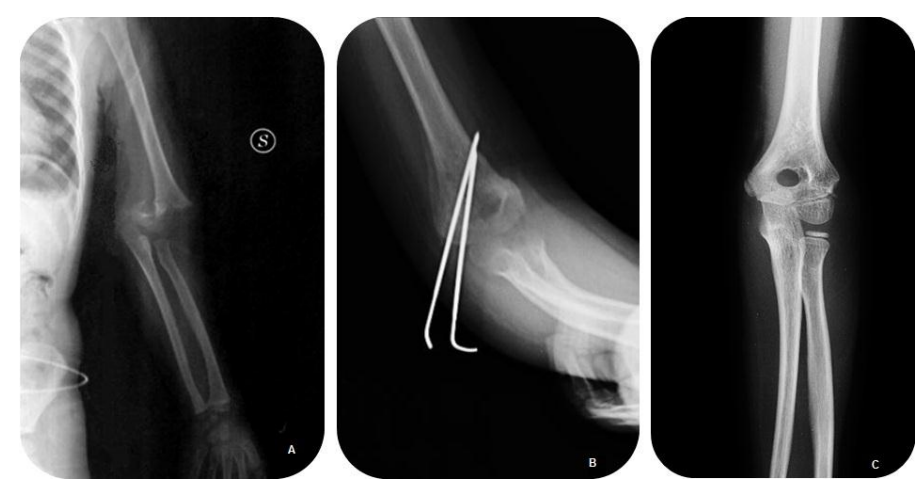

Figure 3. Clinical Case Group 2. (A) Pre-op AP radiograph of lateral-entry pinning; (B) immediate postoperative AP radiograph of lateral-entry pinning; and (C) follow-up after three years.

The subjects were usually discharged the day after treatment and returned for assessment 5-10 days after surgery for clinical and radiographic evaluation. On average, the wires were removed 
four weeks after outpatient $X$-ray control, and each subject received an intensive rehabilitation protocol to restore the full range of motion of the elbow.

The mean follow up was $44 \pm 11.15$ months (range 13-67). According Flynn's criteria, Group 1 had excellent cosmetic outcome in 21 subjects $(94.4 \%)$ and good in one $(5.6 \%)$. The functional factor was satisfactory in 21 patients $(94.4 \%)$. On examination at final follow-up, the range of motion in the treated arm resulted in values for flexion-extension of $103^{\circ} \pm 12.05^{\circ}$ (range $90^{\circ}-130^{\circ}$ ), and supination to pronation of $87^{\circ} \pm 2.42^{\circ}$ (range $82^{\circ}-90^{\circ}$ ). The carrying angle was measured at an average of $4.4^{\circ} \pm 2.11^{\circ}$ (range $2.6^{\circ}-6.5^{\circ}$ ). In one case, a $7.5^{\circ}$ deficit of extension was noticed (Figure $2 \mathrm{C}$ ). In Group 2, the cosmetic and functional factors were satisfactory in all patients (100\%). At the final follow-up, the range of articulation gave a flexion-extension range of about $110.27^{\circ} \pm 14.39^{\circ}$ (range $92^{\circ}-135^{\circ}$ ) and supination to pronation of about $87.7^{\circ} \pm 1.62^{\circ}\left(\right.$ range $\left.85^{\circ}-90^{\circ}\right)$. The difference in the carrying angle was on average $4.46^{\circ} \pm 1.91^{\circ}$ (range $2.8^{\circ}-6.6^{\circ}$ ) (Figure 3C). These data were compared to those of the contralateral limb, and the figures for the average amplitude of movement were similar.

The results of the Mayo Elbow Performance Score (Max 100 points) were: Group 1, 96 points, and Group 2, 98 points (Tables 1-3). Radiographically, measurements of the angle of Baumann between the injured limb and the normal limb were: Group 1 -a difference of $5.3^{\circ} \pm 2.12^{\circ}$ (range $4^{\circ}-6.6^{\circ}$ ), and Group 2-a difference of $4.9^{\circ} \pm 2.82^{\circ}$ (range $3.1^{\circ}-6.7^{\circ}$ ).

Table 1. Twenty-nine patients with displaced (Gartland type III) extension type supracondylar fractures of the humerus randomly treated by closed reduction and percutaneous fixation with crossed medial-lateral pins or two lateral pins; and comparative outcome measures at the last follow-up.

\begin{tabular}{|c|c|c|c|}
\hline Characteristics & $\begin{array}{l}\text { Group 1-K-Wire Cross } \\
\text { Configuration }(n=22)\end{array}$ & $\begin{array}{l}\text { Group 2-Lateral K-Wire } \\
\text { Configuration }(n=13)\end{array}$ & $p$ Value \\
\hline Age * (years) & $6.26 \pm 2.48$ & $5.69 \pm 2.52$ & $0.55^{\alpha}$ \\
\hline Gender + ( $\%$ of patients) & $0.66 \S$ & & \\
\hline Male + & $16(72)$ & $9(73)$ & \\
\hline Female $\dagger$ & $6(28)$ & $4(27)$ & \\
\hline Side $+(\%$ of patients) & $0.53 \S$ & & \\
\hline Left Side $†$ & $15(67)$ & $9(73)$ & \\
\hline Right Side $†$ & $7(33)$ & $4(27)$ & \\
\hline Type of Displacement + ( $\%$ of patients) & $0.59 \S$ & & \\
\hline Posteromedial (III A) + & $17(78)$ & $11(82)$ & \\
\hline Posterolateral (III B) $†$ & $5(22)$ & $2(18)$ & \\
\hline Dynamics of injury + ( $\%$ of patients) & $0.68 \S$ & & \\
\hline Childish games + & $19(89)$ & $12(91)$ & \\
\hline Motor Accident $t$ & $3(11)$ & $1(9)$ & \\
\hline Time between admission to surgery * $(\mathrm{h})$ & $7.8 \pm 2.98$ & $8.64 \pm 3.51$ & $0.49^{\not \alpha}$ \\
\hline Time between injury to admission * $(\mathrm{h})$ & $43.61 \pm 9.5$ & $41.18 \pm 8.5$ & $0.45^{\alpha}$ \\
\hline Follow up * (months) & $44.39 \pm 10.74$ & $42.91 \pm 15.77$ & $0.76^{\not \alpha}$ \\
\hline Flynn Criteria Cosmetic Factor $+(\%$ of patients $)$ & $0.62^{\S}$ & & \\
\hline Excellent & $21(94)$ & $13(100)$ & \\
\hline Good & $1(6)$ & 0 & \\
\hline Fair & 0 & 0 & \\
\hline Poor & 0 & 0 & \\
\hline \multicolumn{4}{|l|}{$\begin{array}{l}\text { Flynn Criteria Functional Factor }+(\% \text { of } \\
\text { patients) }\end{array}$} \\
\hline Flexion-Extension & $103 \pm 12.05$ & $110.27 \pm 14.39$ & 0.16 \\
\hline Supination-Pronation & $87 \pm 2.42$ & $87.7 \pm 1.62$ & 0.39 \\
\hline Modification Carrying Angle (deg) * & $4.4 \pm 2.11$ & $4.46 \pm 1.91$ & $0.94^{\alpha}$ \\
\hline Mayo Elbow Performance Score & $96 / \overline{100}$ & $98 / 100$ & \\
\hline Modification Baumann's Angle (deg) ${ }^{*}$ & $5.3 \pm 2.12$ & $4.9 \pm 2.82$ & $0.53^{\infty}$ \\
\hline Reoperations + & 0 & 0 & $1.0^{\S}$ \\
\hline Return to function + & $0.92 \S$ & & \\
\hline Full + & $21(94)$ & $13(100)$ & \\
\hline Minor Complication † & $4(17)$ & $3(27)$ & \\
\hline Major Complications † & None & None & \\
\hline
\end{tabular}


Table 2. Flynn criteria.

\begin{tabular}{cccc}
\hline Result & Rating & $\begin{array}{c}\text { Cosmetic Factor Loss of } \\
\text { Carrying Angle (Degrees) }\end{array}$ & $\begin{array}{c}\text { Functional Factor } \\
\text { Motion Loss (Degrees) }\end{array}$ \\
\hline \multirow{2}{*}{ Satisfactory } & Excellent & $0-5$ & $0-5$ \\
& Good & $5-10$ & $5-10$ \\
& Fair & $10-15$ & $10-15$ \\
\hline Unsatisfactory & Poor & $>15$ & $>15$ \\
\hline
\end{tabular}

Table 3. Mayo Elbow Performance Score.

\begin{tabular}{ccc}
\hline Feature & Rating & Score \\
\hline \multirow{3}{*}{ Pain Intensity } & None & 45 \\
& Mild & 30 \\
& Moderate & 15 \\
& Severe & 0 \\
Arc of Motion & $>100^{\circ}$ & 20 \\
& $50^{\circ}-100^{\circ}$ & 15 \\
& $<50^{\circ}$ & 5 \\
\hline \multirow{2}{*}{ Stability } & Stable & 10 \\
& Moderate instability & 5 \\
& Grossly Unstable & 0 \\
\hline \multirow{2}{*}{ Function } & Can comb hair & 5 \\
& Can eat & 5 \\
& Can perform hygiene & 5 \\
& Can put on shirt & 5 \\
\hline Maximum Score & Can lace shoe & 5 \\
\hline
\end{tabular}

Complications encountered were: Group 1, in one case, asymmetry of $0.8 \mathrm{~cm}$ was observed with the humerus of the affected limb being longer than the contralateral limb. Two cases had ulnar nerve paresthesia (11.1\%), which resolved spontaneously in about $2-3$ months. One case $(5.5 \%)$ had varus deviation of $6^{\circ}$ and deficits to extension of $7.5^{\circ}$. In Group 2, one case (9\%) had mild hyperextension, and two cases $(18 \%)$ had a local infection $(18 \%)$ treated with antibiotic therapy; one case had the $\mathrm{K}$-wires removed. To date, no patients have required re-operation, there have been no reports of major complications, neurological or vascular, or cases of elbow stiffness. No compartment syndrome were encountered pre- and post-operatively. Currently, all patients could perform daily activities and participate in sports; three of them have embarked on a competitive sporting career. Statistical analysis showed no significant differences between groups (Table 4).

Table 4. Comparative study between the two groups for minor complications

\begin{tabular}{ccc}
\hline Minor Complication + (n. Patients) & Group 1 $(\boldsymbol{n = 2 2 )}$ & Group 2 $(n=\mathbf{1 3})$ \\
\hline Deviation in Varus and deficit to & $1(5)$ & 0 \\
extension & 0 & $1(9)$ \\
Hyperextension & $2(11)$ & 0 \\
Paresthesia & 0 & $2(18)$ \\
Superficial Infections Wires & 0
\end{tabular}

t The data are given as the number (\%) of patients. 


\section{Discussion}

Supracondylar humerus fractures (SCHF) are the most frequent injuries of the elbow region and constitute approximately one third of fractures encountered in children $[2,3,11]$. These fractures typically occur in children aged 2-10 years, and most frequently affect the left limb; they are more common in boys [1]. These fractures are mainly due to low-energy trauma and are classified according to the damaging fracture mechanism. These occur in extension by falling on to the palm of the hand with a hyperextended elbow (the most frequent) as well as in direct falling onto the elbow when flexed.

At clinical examination, children present a distinct clinical picture-they complain of spontaneous and continuous pain exacerbated by palpation with functional limitations of the higher limb in flexion and of the forearm in semi-pronation. The shoulder of the injured limb is lowered relative to the contralateral limb. They have swelling that extends to include both the upper arm and the forearm and purplish bruising in the antero-medial region of the elbow [14].

In classifying fractures occurring in extension, the system most widely used and reproducible is the Gartland classification [4,15]. Wilkins [17] later introduced modifications of this system for displaced fractures, on the basis of the direction of the shift in the coronal plane of the distal fragment. This results in two types (IIIA and IIIB). This system has improved the clinical utility of the Gartland classification and assists with detection of future complications and choice of treatment.

Since diagnosis is based on clinical and instrumental data through the use of conventional radiology, it is rarely necessary to perform more sophisticated investigations. The periosteum plays a decisive role in maintaining stability after fracture but the highly complex anatomy of this region due to the presence of numerous secondary centers of ossification can lead to early and late complications if fractures are not detected in time.

The timing of treatment is controversially discussed in the literature. Indeed, delaying treatment of this fracture did not have a significant influence on the rates of open reduction, complication, or overall outcome [18].

According to Oetgen et al. [19], five risk factors identify complications in the treatment of SCHF: younger patient age, left sided fractures, type 3 fractures, peri-operative nerve palsy and post-operative infections. Rotation and coronal plane displacement were reported by Flierl et al. [20] as predictive of complications with need for physical or occupational therapy and nerve injury. Malunion is a complication of SCHF treatment that occurs during an arthroscopic approach. Koehler et al. [21] showed that arthroscopy is useful and favorable and offers deformity correction and safe access of the anterior humerus as well as minimal dissection, scarring and intracapsular contractures.

The literature describes various methods of positioning the K-wires. The cross-wired configuration has been demonstrated, in biomechanical studies and clinical trials, to be a more stable configuration than the lateral wire configuration [22,23]. A previous study showed greater resistance to internal rotation of the cross-wired configuration [24]. For this reason, this configuration has been employed for several years and guaranteed higher stability. However, Slobogean et al. [12] reported that the cross-wired configuration leads to an increased risk of iatrogenic damage to the ulnar nerve versus a lateral K-wire [25].

Recent studies have claimed that the use of two lateral wires gives good stability, but involvement of the ulnar nerve may be more frequent [11,26]. In addition, if the K-wires are not well positioned, then the potential risk of iatrogenic injuries as well as potential loss of reduction of the fracture increases $[27,28]$.

Sibinski et al. [24] and Zamzam et al. [29] suggested that lateral entry pinning increases stability. It also allows extension of the forearm and the addition of a third and K-wire medially to further increase stability.

Each orthopedic surgeon choosees the type of configuration to use according to their judgment and their own experiences and characteristics in accordance with the anatomical/clinical picture of fracture as well as patient age [12]. 
According to Yen and Kocher [30], we can conclude that there is no significant difference between the two techniques with regard to changes in flexion-extension, pronation and supination of carrying angle, the angle of Baumann, ability to return to daily activities or the incidence of complications.

We found two local infections (18\%) in the group treated with lateral K-wires similar to the literature [31]. For this reason, Gaston et al. [32] recommended oral antibiotic therapy to minimize the risk of these complications.

In our study group, 22 patients were treated with the cross-wired configuration and 13 by the lateral-wire configuration. Both groups achieved a good recovery of elbow motion without the onset of any neurovascular complications, severe deformities, stiffness or elbow disability.

Longitudinal clinical evaluation showed that, in general, children treated for supracondylar humeral fractures had good outcomes on the Flynn and the Mayo Elbow Performance Score. They enjoyed restoration of range of motion with satisfied parents [33-36]. Radiographic evaluation of Baumann's angle proved very useful for assessing pre- and post-operative changes.

Thus, we suggest that there is no significant difference between the use of cross and lateral K-wire configurations-both groups have good outcomes. The two methods were comparable, both from clinical and radiographic points of view, even if a greater potential risk of neurovascular injury exists in the cross K-wired configuration than the lateral K-wire.

\section{Conclusions}

In our study both groups achieved a satisfying outcome with similar results in joint function recovery and complications.

Author Contributions: The data were abstracted by 3 of us (Maria Riccioli, Gianluca Testa, Ludovico Lucenti), all procedures were performed by 4 of us (Vito Pavone, Giuseppe Condorelli, Sergio Avondo, Giuseppe Sessa), and the outcome measurements and statistical analysis were undertaken by 1 of us (Claudia de Cristo).

Conflicts of Interest: The authors declare no conflict of interest.

\section{References}

1. Babal, J.C.; Mehlman, C.T.; Klein, G. Nerve injuries associated with pediatric supracondylar humeral fractures: A meta-analysis. J. Pediatr. Orthop. 2010, 30, 253-263. [CrossRef] [PubMed]

2. Omid, R.; Choi, P.D.; Skaggs, D.L. Supracondylar humeral fractures in children. J. Bone Joint Surg. Am. 2008, 90, 1121-1132. [PubMed]

3. Robb, J.E. The pink, pulseless hand after supracondylar fracture of the humerus in children. J. Bone Joint Surg. Br. 2009, 91, 1410-1412. [CrossRef] [PubMed]

4. Barron-Torres, E.A.; Sanchez-Cruz, J.F.; Cruz-Melendez, J.R. Clinical and epidemiological characteristic of humeral supracondylar fractures in pediatric patients in a Regional General Hospital. Cir. Cir. 2015, 83, 29-34. [PubMed]

5. De Pellegrin, M.; Brivio, A.; Pescatori, E.; Tessari, L. Supracondylar humerus fractures in children: Closed reduction and cross pin fixation in prone position. GIOT. 2008, 34, 199-204.

6. Dua, A.; Eachempati, K.K.; Malhotra, R.; Sharma, L.; Gidaganti, M. Closed reduction and percutaneous pinning of displaced supracondylar fractures of humerus in children with delayed presentation. Chin. J. Traumatol. 2011, 14, 14-19. [PubMed]

7. Eren, A.; Güven, M.; Erol, B.; Cakar, M. Delayed surgical treatment of supracondylar humerus fractures in children using a medial approach. J. Child Orthop. 2008, 2, 21-27. [PubMed]

8. Gupta, N.; Kay, R.M.; Leitch, K.; Femino, J.D.; Tolo, V.T.; Skaggs, D.L. Effect of surgical delay on perioperative complications and need for open reduction in supracondylar humerus fractures in children. J. Pediatr. Orthop. 2004, 24, 245-248. [PubMed]

9. Mangwani, J.; Nadarajah, R.; Paterson, J.M. Supracondylar humeral fractures in children: Ten years' experience in a teaching hospital. J. Bone Joint Surg. Br. 2006, 88, 362-365. [CrossRef] [PubMed]

10. Mommsen, P.; Zeckey, C.; Hildebrand, F.; Frink, M.; Khaladj, N.; Lange, N.; Krettek, C.; Probst, C. Traumatic extremity arterial injury in children: Epidemiology, diagnostics, treatment and prognostic value of Mangled Extremity Severity Score. J. Orthop. Surg. Res. 2010, 15, 25-35. 
11. Pretell-Mazzini, J.; Rodriguez-Martin, J.; Andres-Esteban, E.M. Does open reduction and pinning affect outcome in severely displaced supracondylar humeral fractures in children? A systematic review. Strateg. Trauma Limb Reconstr. 2010, 2, 57-64. [CrossRef] [PubMed]

12. Slobogean, B.L.; Jackman, H.; Tennant, S. Iatrogenic ulnar nerve injury after the surgical treatment of displaced supracondylar fractures of the humerus: Number needed to harm, a systematic review. J. Pediatr. Orthop. 2010, 30, 430-436. [CrossRef] [PubMed]

13. Flynn, J.C.; Matthews, J.G.; Benoit, R.L. Blind pinning of displaced supracondylar fractures of the humerus in children. Sixteen years' experience with long-term follow-up. J. Bone Joint Surg. Am. 1974, 56, 263-272. [PubMed]

14. Longo, U.G.; Franceschi, F.; Loppini, M.; Maffulli, N.; Denaro, V. Rating systems for evaluation of the elbow. Br. Med. Bull. 2008, 87, 131-161. [CrossRef] [PubMed]

15. Mallo, G.; Stanat, S.J.; Gaffney, J. Use of the Gartland classification system for treatment of pediatric supracondylar humerus fractures. Orthopedics 2010, 33. [CrossRef] [PubMed]

16. Silva, M.; Pandarinath, R.; Farng, E.; Park, S.; Caneda, C.; Fong, Y.J.; Penman, A. Inter- and intra-observer reliability of the Baumann angle of the humerus in children with supracondylar humeral fractures. Int. Orthop. 2010, 34, 553-557. [CrossRef] [PubMed]

17. Wilkins, K.E. The operative management of supracondylar fractures. Orthop. Clin. North Am. 1990, 21, 269-289. [PubMed]

18. Schmid, T.; Joeris, A.; Slongo, T.; Ahmad, S.S.; Ziebarth, K. Displaced supracondylar humeral fractures: Influence of delay of surgery on the incidence of open reduction, complications and outcome. Arch. Orthop. Trauma Surg. 2015, 135, 963-969. [CrossRef] [PubMed]

19. Oetgen, M.E.; Mirick, G.E.; Atwater, L.; Lovejoy, J.F. Complications and predictors of need for return to the operating room in the treatment of supracondylar humerus fractures in children. Open Orthop. J. 2015, 9, 139-142. [CrossRef] [PubMed]

20. Flierl, M.A.; Carry, P.M.; Scott, F.; Georgopoulos, G.; Hadley-Miller, N. Rotation and displacement predict adverse events in pediatric supracondylar fractures. Orthopedics 2015, 38, e690-e695. [CrossRef] [PubMed]

21. Koehler, S.M.; Sakamoto, S.; Abernathie, B.L.; Hausman, M.R. Arthroscopic correction of a supracondylar malunion in a child. Arthorosc. Technol. 2015, 4, e215-e221. [CrossRef] [PubMed]

22. Brauer, C.A.; Lee, B.M.; Bae, D.S.; Waters, P.M.; Kocher, M.S. A systematic review of medial and lateral entry pinning versus lateral entry pinning for supracondylar fractures of the humerus. J. Pediatr. Orthop. 2007, 27, 181-186. [CrossRef] [PubMed]

23. Larson, L.; Firoozbakhsh, K.; Passarelli, R.; Bosch, P. Biomechanical analysis of pinning techniques for pediatric supracondylar humerus fractures. J. Pediatr. Orthop. 2006, 26, 573-578. [CrossRef] [PubMed]

24. Sibinski, M.; Sharma, H.; Sherlock, D.A. Lateral versus crossed wire fixation for displaced extension supracondylar humeral fractures in children. Injury 2006, 37, 961-965. [CrossRef] [PubMed]

25. Zhao, J.G.; Wang, J.; Zhang, P. Is lateral pin fixation for displaced supracondylar fractures of the humerus better than crossed pins in children? Clin. Orthop. Relat. Res. 2013, 471, 2942-2953. [CrossRef] [PubMed]

26. Lee, S.; Park, M.S.; Chung, C.Y.; Kwon, D.G.; Sung, K.H.; Kim, T.W.; Choi, I.H.; Cho, T.J.; Yoo, W.J.; Lee, K.M. Consensus and different perspectives on treatment of supracondylar fractures of the humerus in children. Clin. Orthop. Surg. 2012, 4, 91-97. [CrossRef] [PubMed]

27. El-Adl, W.A.; El-Said, M.A.; Boghdady, G.W.; Ali, A.S. Results of treatment of displaced supracondylar humeral fractures in children by percutaneous lateral cross-wiring technique. Strateg. Trauma Limb Reconstr. 2008, 3, 1-7. [CrossRef] [PubMed]

28. Sankar, W.N.; Hebela, N.M.; Skaggs, D.L.; Flynn, J.M. Loss of pin fixation in displaced supracondylar humeral fractures in children: Causes and prevention. J. Bone Joint Surg. Am. 2007, 89, 713-717. [CrossRef] [PubMed]

29. Zamzam, M.M.; Bakarman, K.A. Treatment of displaced supracondylar humeral fractures among children: Crossed versus lateral pinning. Injury 2009, 40, 625-630. [CrossRef] [PubMed]

30. Yen, Y.M.; Kocher, M.S. Lateral entry compared with medial and lateral entry pin fixation for completely displaced supracondylar humeral fractures in children. Surgical technique. J. Bone Joint Surg. Am. 2008, 90, 20-30. [CrossRef] [PubMed]

31. Skaggs, D.L.; Cluck, M.W.; Mostofi, A.; Flynn, J.M.; Kay, R.M. Lateral-entry pin fixation in the management of supracondylar fractures in children. J. Bone Joint Surg. Am. 2004, 86, 702-707. [PubMed] 
32. Gaston, R.G.; Cates, T.B.; Devito, D.; Schmitz, M.; Schrader, T.; Busch, M.; Fabregas, J.; Rosenberg, E.; Blanco, J. Medial and lateral pin versus lateral-entry pin fixation for Type 3 supracondylar fractures in children: A prospective, surgeon-randomized study. J. Pediatr. Orthop. 2010, 30, 799-806. [CrossRef] [PubMed]

33. Ladenhauf, H.N.; Schaffert, M.; Bauer, J. The displaced supracondylar humerus fracture: Indications for surgery and surgical options: A 2014 update. Curr. Opin. Pediatr. 2014, 26, 64-69. [CrossRef] [PubMed]

34. Mulpuri, K.; Wilkins, K. The treatment of displaced supracondylar humerus fractures: Evidence-based guideline. J. Pediatr. Orthop. 2012, 32, S143-S152. [CrossRef] [PubMed]

35. Spencer, H.T.; Wong, M.; Fong, Y.J.; Penman, A.; Silva, M. Prospective longitudinal evaluation of elbow motion following pediatric supracondylar humeral fractures. J. Bone Joint Surg. Am. 2010, 92, 904-910. [CrossRef] [PubMed]

36. Zionts, L.E.; Woodson, C.J.; Manjra, N.; Zalavras, C. Time of return of elbow motion after percutaneous pinning of pediatric supracondylar humerus fractures. Clin. Orthop. Relat. Res. 2009, 467, 2007-2010. [CrossRef] [PubMed]

(C) 2016 by the authors; licensee MDPI, Basel, Switzerland. This article is an open access article distributed under the terms and conditions of the Creative Commons by Attribution (CC-BY) license (http:/ / creativecommons.org/licenses/by/4.0/). 